\title{
Phase Composition in NiTi Near-Surface Layers after Electron Beam Treatment and its Variation Depending on Beam Energy Density
}

\author{
Marina G. Ostapenko ${ }^{1,2, a)}$, Ludmila L. Meisner ${ }^{1,3, b)}$, \\ Aleksandr I. Lotkov ${ }^{1, c)}$, and Ekaterina Y. Gudimova ${ }^{1,}$ d) \\ ${ }^{1}$ Institute of Strength Physics and Materials Science SB RAS, Tomsk, 634055, Russia \\ ${ }^{2}$ National Research Tomsk Polytechnic University, Tomsk, 634050, Russia \\ ${ }^{3}$ National Research Tomsk State University, Tomsk, 634050, Russia \\ a) Corresponding author: artifakt@ispms.tsc.ru \\ b) $11 \mathrm{~m} @$ ispms.tsc.ru \\ c) lotkov@ispms.tsc.ru \\ d) egu@ispms.tsc.ru
}

\begin{abstract}
In the work, we study the mechanisms of structural phase state formation in NiTi surface layers after lowenergy pulsed electron beam irradiation depending on the electron beam energy density. It is revealed that after electron beam treatment of the NiTi specimens at energy densities $E_{1}=15 \mathrm{~J} / \mathrm{cm}^{2}, E_{2}=20 \mathrm{~J} / \mathrm{cm}^{2}$, and $E_{3}=30 \mathrm{~J} / \mathrm{cm}^{2}$, a series of effects is observed: the absence of the $\mathrm{Ti}_{2} \mathrm{Ni}$ phase and the presence of new peaks correspond to the $\mathrm{B}^{\prime} 9^{\prime}$ martensite phase with monoclinic structure. Estimation of the relative volume content of the B2 and B19' phases from the total intensity of their peaks shows that the percentage of the martensite phase increases from $\sim 5$ vol.\% in the NiTi specimen irradiated at $E_{1}=15 \mathrm{~J} / \mathrm{cm}^{2}$ to $\sim 80 \mathrm{vol} . \%$ in the NiTi specimen irradiated at $E_{3}=30 \mathrm{~J} / \mathrm{cm}^{2}$. It is found that in the NiTi specimens irradiated at $E \leq 20 \mathrm{~J} / \mathrm{cm}^{2}$, the layer that contains a martensite phase resides not on the surface but at some depth from it.
\end{abstract}

Keywords: nickel-titanium alloy, low-energy high-current electron beams, structural phase states, B2 phase, B19' martensite phase, X-ray diffraction analysis, residual stresses

\section{INTRODUCTION}

NiTi shape-memory alloys are typical representatives of a class of materials, physical and mechanical properties are strongly dependent on the structural-phase state and the chemical composition of the alloy [1]. Previous studies $[2,3]$ have shown that the surface modification of TiNi-based alloys by low-energy electron beams leads to an increase in their corrosion resistance, fatigue resistance, surface hardening. At the same time, the final surface microstructure and properties of electron beam-treated materials depend directly on the treatment parameters: on the electron beam energy density, pulse duration, and number of pulses [2]. Therefore, attaining the best surface properties of NiTi alloy requires studies to provide an optimum choice of these parameters.

It is known that the modification of electron beams induces dynamic temperature fields in the surface of the material, giving rise to superfast heating and melting, as well as a dynamic stress field that causes intense deformation at the material surface [4]. So, nonequilibrium structural phase states may arise not only in the regions of direct electron beam action but also in the underlying layers of treated materials. Therefore, the surface properties of NiTi alloy after electron beam surface treatment are defined by the structural phase state in its surface layer.

The objective of the work was to study the mechanisms of structural phase state formation in NiTi surface layers after low-energy pulsed electron beam irradiation depending on the electron beam energy density.

(C) 2014 AIP Publishing LLC 978-0-7354-1260-6/\$30.00 


\section{MATERIALS AND RESEARCH TECHNIQUES}

The alloy under study was melted from iodide titanium and NO-grade nickel in an electric arc furnace (with sixfold remelting of the ingot). The initial NiTi specimens at room temperature were in the two-phase state: a B2 phase $\left(\sim 95\right.$ vol. $\%$ ) and a $\mathrm{Ti}_{2} \mathrm{Ni}$ phase ( $\sim 5$ vol.\%). The start temperature of direct $\mathrm{B} 2 \rightarrow \mathrm{B} 19^{\prime}$ martensite transformation for the alloy was $M_{\mathrm{S}}=290 \mathrm{~K}$. The equipment used in the study and mentioned hereinafter was provided by Shared Use Center "Nanotekh" of ISPMS SB RAS. The chemical composition of the B2 phase was measured with a Wave 500 wavelength dispersive spectrometer and an EVO 50 scanning electron microscope. According to the obtained data, the $\mathrm{Ti}-\mathrm{Ni}$ ratio in the $\mathrm{B} 2$ phase corresponded to $\mathrm{Ti}_{49.5} \mathrm{Ni}_{50.5}$. The NiTi specimens were subjected to pulsed (pulse duration $\tau=150 \mu \mathrm{s}$, number of pulses $=5)$ surface irradiation by a low-energy high-current $(I=70 \mathrm{~A})$ electron beam with surface melting under the conditions of high vacuum $\left(\sim 10^{-6} \mathrm{~Pa}\right)$ with oilless pumping. The beam energy density was constant $\left(E=\right.$ const) and was either $E_{1}=15 \mathrm{~J} / \mathrm{cm}^{2}$, or $E_{2}=20 \mathrm{~J} / \mathrm{cm}^{2}$, or $E_{3}=30 \mathrm{~J} / \mathrm{cm}^{2}$. X-ray diffraction (XRD) analysis was performed at room temperature on a DRON-7 diffractometer in Co-K $\alpha$ radiation with a Fe-filter for cutoff of $\mathrm{K}_{\beta}$-radiation. The phase composition and the structure of surface and deeper layers were analyzed using $\mathrm{X}$-ray diffraction in symmetric (Bragg-Brentano) and asymmetric geometries. Here we consider that the data obtained from diffraction patterns in symmetric Bragg diffraction geometry characterize the specimen structure in the material bulk, and those obtained from diffraction patterns in asymmetric geometry characterize the structure of a layer whose thickness corresponds to a chosen glancing incidence angle $\alpha$.

The microstructure of NiTi near-surface layers before and after electron beam treatment was examined on a JEM 2100 transmission electron microscope (JEOL, Japan) at an accelerating voltage of $200 \mathrm{kV}$. Foils of lateral sections for transmission electron microscopy were prepared by a special procedure which allowed one to preserve the irradiated surface and to examine the structure at a specified depth from the surface.

\section{RESULTS AND DISCUSSION}

Figure 1 shows X-ray diffraction patterns in symmetric geometry for NiTi before (a) and after electron beam treatment $(b-d)$. It is seen that the X-ray pattern of the initial NiTi specimen contains peaks of only two phases: B2 (NiTi) and $\mathrm{Ti}_{2} \mathrm{Ni}$. The $\mathrm{B} 2$ phase is textured such that the X-ray pattern lacks the main $(200)_{\mathrm{B} 2}$ peak (in the range of angles $2 \theta \sim 71^{\circ}-72^{\circ}$ ).

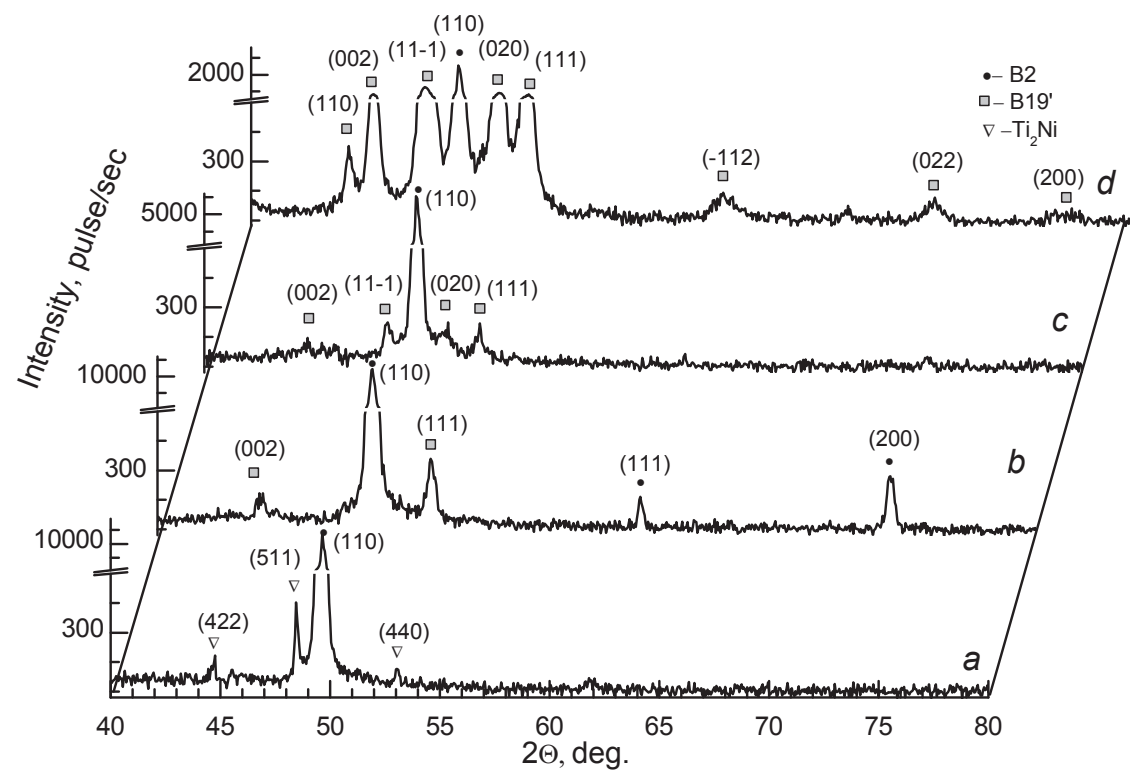

FIGURE 1. Fragments of X-ray patterns for initial NiTi (a) and NiTi irradiated at $E=15$ (b), 20 (c), and $30 \mathrm{~J} / \mathrm{cm}^{2}$ (d). Bragg-Brentano geometry (symmetric), $\mathrm{Co}-\mathrm{K}_{\alpha}$ radiation 

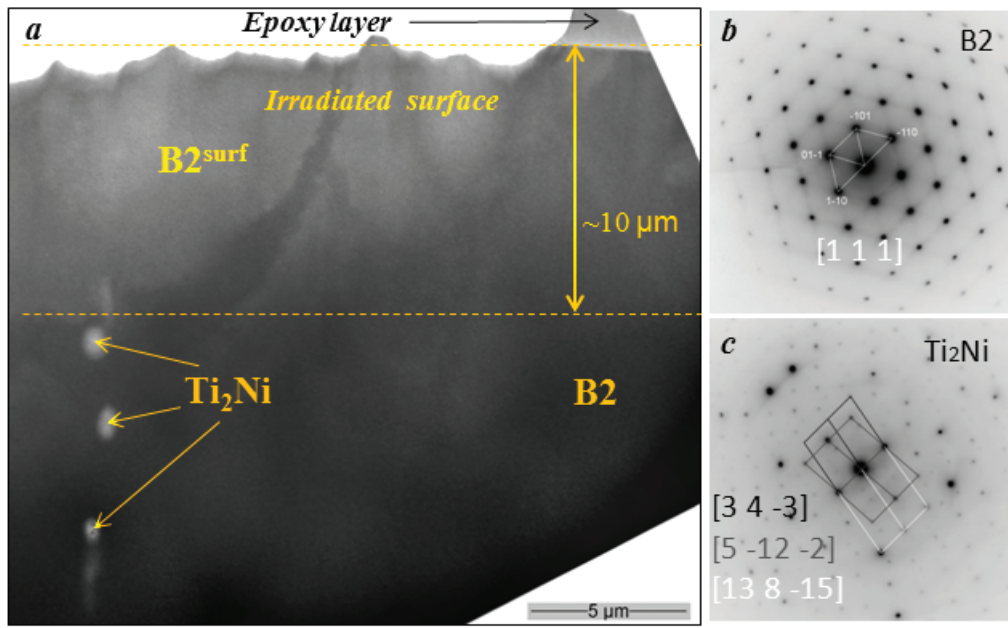

FIGURE 2. Bright-field image of near-surface microstructure for NiTi irradiated at $E_{1}=15 \mathrm{~J} / \mathrm{cm}^{2}$ (a) and microdiffraction patterns for $\mathrm{B}^{\text {surf }}(\mathrm{b})$ and $\mathrm{Ti}_{2} \mathrm{Ni}(\mathrm{c})$

After electron beam treatment of the NiTi specimens at different energy densities $E_{1}=15 \mathrm{~J} / \mathrm{cm}^{2}(\mathrm{~b}), E_{2}=$ $20 \mathrm{~J} / \mathrm{cm}^{2}(\mathrm{c})$, and $E_{3}=30 \mathrm{~J} / \mathrm{cm}^{2}(\mathrm{~d})$, a series of common effects is observed on all X-ray patterns: (1) the presence of new peaks the most intense of which are found in the vicinity of the $(110)_{\mathrm{B} 2}$ peak; (2) the absence of peaks of the $\mathrm{Ti}_{2} \mathrm{Ni}$ phase; (3) the appearance of the $(200)_{\mathrm{B} 2}$ peak on the X-ray pattern (b) suggesting that the $\mathrm{B} 2$ phase texture is changed after electron beam treatment of the NiTi specimens at $E_{1}=15 \mathrm{~J} / \mathrm{cm}^{2}$. Interpretation of the X-ray patterns shows that the new peaks correspond to the $\mathrm{B} 19^{\prime}$ martensite phase with monoclinic structure (space group $\mathrm{P} 2_{1} / \mathrm{m}$ ). Comparison of the X-ray patterns reveals that increasing the electron beam energy density increases the intensity of B19' peaks. Estimation of the relative volume content of the B2 and B19' phases from the total intensity of their peaks shows that the percentage of the martensite phase increases from $\sim 5$ vol. $\%$ in the NiTi specimen irradiated at $E_{1}=15 \mathrm{~J} / \mathrm{cm}^{2}$ to $\sim 80 \mathrm{vol} . \%$ in the NiTi specimen irradiated at $E_{3}=30 \mathrm{~J} / \mathrm{cm}^{2}$. The presented experimental data demonstrate that electron beam treatment changes the structural phase states in NiTi near-surface zones beneath the irradiated surface. At the same time, the data give no way to determine which of these changes occur in the modified layers and in the layers beneath them. To identify the contributions of these layers to the X-ray diffraction patterns and to assess the structural and phase states formed in them after irradiation, all specimens were studied by X-ray diffraction in asymmetric geometry at glancing angles $\alpha_{1}=3^{\circ}$ (the layer thicknesses $h$ is from $\sim 0.3$ to $\sim 2.8 \mu \mathrm{m}$ ), $\alpha_{2}=$ $6^{\circ}(h \sim 0.5 \div 5.2 \mu \mathrm{m})$, and $\alpha_{3}=12^{\circ}(h \sim 0.9 \div 20 \mu \mathrm{m})$. The study shows that in the NiTi specimens irradiated at $E_{1}=$ $15 \mathrm{~J} / \mathrm{cm}^{2}$ and $E_{2}=20 \mathrm{~J} / \mathrm{cm}^{2}$, decreasing the glancing angle $\alpha$, i.e., decreasing the analyzed layer thickness, decreases the intensity of $\mathrm{B} 19^{\prime}$ peaks on the X-ray pattern to the point of almost complete disappearance at the least glancing angle $\alpha=3^{\circ}$ used in the study.

Another situation is observed in the NiTi specimens irradiated at $E_{3}=30 \mathrm{~J} / \mathrm{cm}^{2}$. The X-ray patterns in both symmetric geometry and asymmetric geometry reveal intense peaks of the B19' phase, whereas peaks of the B2 phase are much less intense. Decreasing the glancing angle does not cause any decrease in the intensity of B19.' peaks, as opposed to the two previous cases.

From the obtained data it follows that although the martensite phase with B19' structure appears in the NiTi near-surface region in all modes of electron beam treatment, the amount of this phase depends on the electron beam energy density $E$ : the lower the energy density, the smaller the martensite amount. Besides, the localization region of the martensite phase also depends on the electron beam energy density. In the NiTi specimens irradiated at lower beam energy densities, the layer that contains the martensite phase resides not on the surface but at some depth from it. On the contrary, in the NiTi specimen irradiated at the highest electron beam energy density, the entire nearsurface region is in a two-phase state (B2 and B19') with the volume fraction of the B19' martensite phase far greater than that of the B2 phase. The results of X-ray examination of the phase composition in NiTi near-surface regions after electron beam treatment agree with data of transmission electron microscopy (TEM). Figure 2(a) shows a bright-field TEM image of the microstructure in the layer adjacent to the surface of the NiTi specimen 
irradiated at $E_{1}=15 \mathrm{~J} / \mathrm{cm}^{2}$. In this outer layer of thickness $\sim 10 \mu \mathrm{m}$, the microstructure characteristic of martensite phases is not observed and $\mathrm{Ti}_{2} \mathrm{Ni}$ particles are absent. The microdiffraction patterns of the layer (Fig. 2(b)) correspond to an ordered B2 structure. Particles of the $\mathrm{Ti}_{2} \mathrm{Ni}$ phase are found only at a depth of $8-10 \mu \mathrm{m}$ from the surface, as evidenced by the bright-field images of the microstructure (Fig. 2(a)) and microdiffraction patterns of these particles (Fig. 2(c)). Similar results of microstructure analysis were obtained for the specimens irradiated at $E_{1}=20 \mathrm{~J} / \mathrm{cm}^{2}$. It is revealed that in the near-surface region of the NiTi specimen irradiated at $E_{3}=30 \mathrm{~J} / \mathrm{cm}^{2}$ the microstructure typical of lath martensite with a bimodal internal structure is found not only in the immediate proximity to the irradiated surface (in a layer of thickness less than $10 \mu \mathrm{m}$ ) but also at a larger depth. It should be noted that according to the data of electron microscopy, the surface layer after irradiation at $E_{3}=30 \mathrm{~J} / \mathrm{cm}^{2}$ was free of $\mathrm{Ti}_{2} \mathrm{Ni}$ particles, like in the previous two cases.

\section{CONCLUDING REMARKS}

The conducted study demonstrates the following. After electron beam treatment of NiTi at beam energy densities $E_{1}=15 \mathrm{~J} / \mathrm{cm}^{2}, E_{2}=20 \mathrm{~J} / \mathrm{cm}^{2}$, and $E_{3}=30 \mathrm{~J} / \mathrm{cm}^{2}$, a phase with B19' martensite structure is formed beneath the irradiated surface with the phase amount and localization dependent on the electron beam energy density. In the NiTi specimens irradiated at $E \leq 20 \mathrm{~J} / \mathrm{cm}^{2}$, the layer containing the martensite phase is found not on the surface but at some depth from it. In the NiTi specimen irradiated at $E_{3}=30 \mathrm{~J} / \mathrm{cm}^{2}$, the entire near-surface region (including the modified outer layer of depth $\sim 10 \mu \mathrm{m}$ ) is characterized by a two-phase state (B2 and B19') in which the B19' martensite phase dominates over the B2 phase. It is found that the lower the beam energy density, the smaller the martensite amount. In the irradiated NiTi specimens, the modified outer layer (melted and quenched) is free from $\mathrm{Ti}_{2} \mathrm{Ni}$ particles which are present in large amount in the specimens before treatment.

The authors are thankful to Professor N.N. Koval, Head of Laboratory of Plasma Emission Electronics of IHCE SB RAS, for help in organizing the electron beam treatment of NiTi specimens and to A.D. Teresov, Lead Electronic Engineer, for conduction of the treatment.

The work was performed under project of SB RAS No. III.23.2.1 and supported by Scholarship Fund of the President of the Russian Federation (SP-236.2012.4).

\section{REFERENCES}

1. J. Ryhanen, Biocompatibility evaluation of nickel-titanium shape memory metal alloy (Oulun Yliopisto, 1999).

2. K. M. Zhang, D. Z. Yang, J. X. Zou, T. Grosdidier, and C. Dong, Surf. Coat. Technol. 201(6), 3096 (2006).

3. A. I. Lotkov, et al., Surface Nanoengineering. Formation of Nonequilibrium States in Surface Layers of Materials by Electron-Ion Plasma Technologies, edited by I. Z. Lyakhov and S. G. Psakhie (Publ. House of SB RAS, Novosibirsk, 2008), p. 276.

4. L. L. Meisner, A. A. Lotkov, M. G. Ostapenko, and E. Yu. Gudimova, Fiz. Mezomekh. 15(3), 79 (2012). 